\section{Current approaches}

\section{in chronic pain}

\section{Christopher Bass MD FRCPsych,}

Consultant Liaison Psychiatrist, Department

of Psychological Medicine, John Radcliffe

Hospital, Oxford

Tim Jack MB FRCA DA,

Consultant Anaesthetist, Pain Relief Unit,

Churchill Hospital, Oxford

Clin Med JRCPL 2002;2:505-8

\section{Prevalence of chronic pain in different clinical settings}

Croft et al $^{1}$ found a prevalence of chronic widespread pain in $11.2 \%$ of the population. About one in six of these individuals has significant psychological problems, but rates of psychiatric morbidity are even higher in patients attending rheumatology outpatient clinics and pain clinics in general hospitals (Fig 1). These findings suggest that psychological assessment of patients with chronic pain is an important task. This article will attempt to describe current methods of assessing and managing these patients.

\section{Components of psychological assessment}

Several indicators should alert the physician to the importance of psychosocial factors in chronic pain (Table 1). It should be made clear to the patient at the outset that all pain has a psychological component, and that both physical and psychological factors are important in chronic pain. One way of introducing this concept to the patient at the initial interview is to say the following:

We want to help you with your pain, and we believe it is real, not imagined or in your mind. However, all pain has physical and emotional aspects, and both may be making a contribution to your symptoms at present. It is as important to address the psychological aspects as the physical ones in all patients with difficult chronic pain like yours.

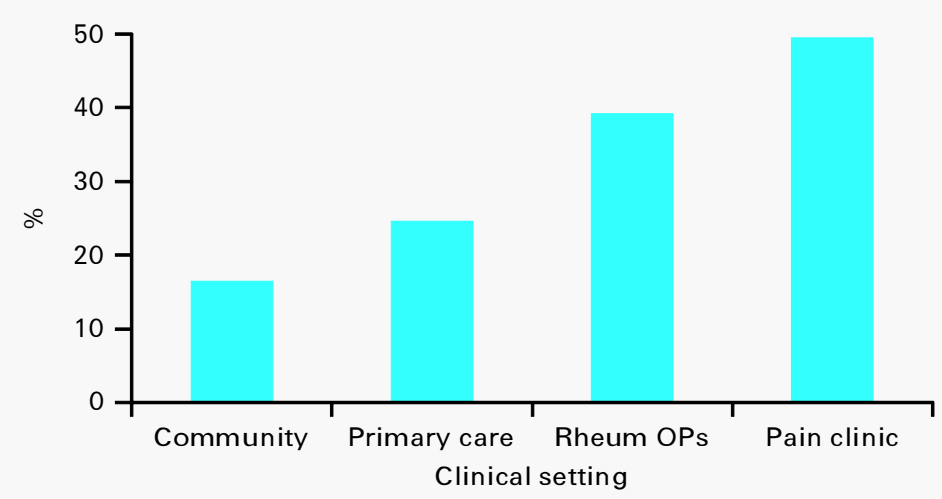

Fig 1. Prevalence of psychiatric morbidity in patients with widespread chronic pain (Rheum OPs = rheumatology outpatients).

Table 1. Indications that psychosocial factors are important in patients with pain (adapted from Ref 2).

- Previous history of medically unexplained physical symptoms

- Disparity between objective findings and functional disability

- Excessive use of healthcare system

- Signs or symptoms of psychiatric disorder

- Prolonged, excessive or inappropriate use of opiates, benzodiazepines or alcohol

\section{The initial interview}

The first objective of assessment is to understand why this particular person became ill in this particular way at this particular time (Table 2). This cannot always be accomplished in a single interview, especially a short one.

It is important to accept the patient's symptoms as real. A sensible way to start is by asking the patient what other physicians have said about the causes of the pain. This can lead naturally to asking about the patient's own views and beliefs about their pain.

It is advisable to proceed with the interview in a sequence, starting with the complaints of pain then moving on to psychological and social aspects as the interview progresses (Fig 2). A chronological account of all current physical complaints is the natural starting point, including contacts with other doctors and therapists, treatments received (including alternative treatments) and their effects. Patients should then be asked about any disability, limitations of activity or avoidances.

Enquiries should be made about any illness in the parents, for example leading to parental invalidism, how the family coped with pain and illness, and the impact of these illnesses on the patient. This overlaps with a personal history, enquiring particularly about experience of, and attitudes to, illness in the family

Table 2. Objectives in first assessment interview.

- Clarify the patient's complaints

- Understand what the patient wants

- Elicit fears and beliefs about the pain

- Elicit contribution of the relevant organic disease to the patient's pain complaints

- Identify relevant psychosocial stressors (antecedent and current)

- Identify salient maintaining factors*

- Identify psychiatric disorder (or relevant psychophysiological processes, such as hyperventilation or increased muscle tension)

\footnotetext{
* see Table 5
} 
during the patient's upbringing ${ }^{3,4}$. For those who have had physical illnesses as a child, it is important to ask what kinds of illness, what incapacity resulted, and whether this led to any prolonged school absences. It might be appropriate at this stage to enquire about any physical, emotional or sexual abuse experienced by the patient, but this depends on the confidence of the interviewer and the willingness of the patient to discuss such issues.

The clinician should then ask about beliefs and attitudes regarding the symptoms as well as attitudes to the medical profession and to health and illness generally. A useful question is: 'What is your worst fear?' It is often helpful to ask about a typical day, with the patient describing patterns of pain and behaviour on an hourly basis throughout the day. This may provide further evidence of disability and mood.

Current mood should be carefully assessed, paying specific attention to symptoms of depression, panic and anxiety. It is important to ask about any

Fig 2. Suggested sequence of interview.

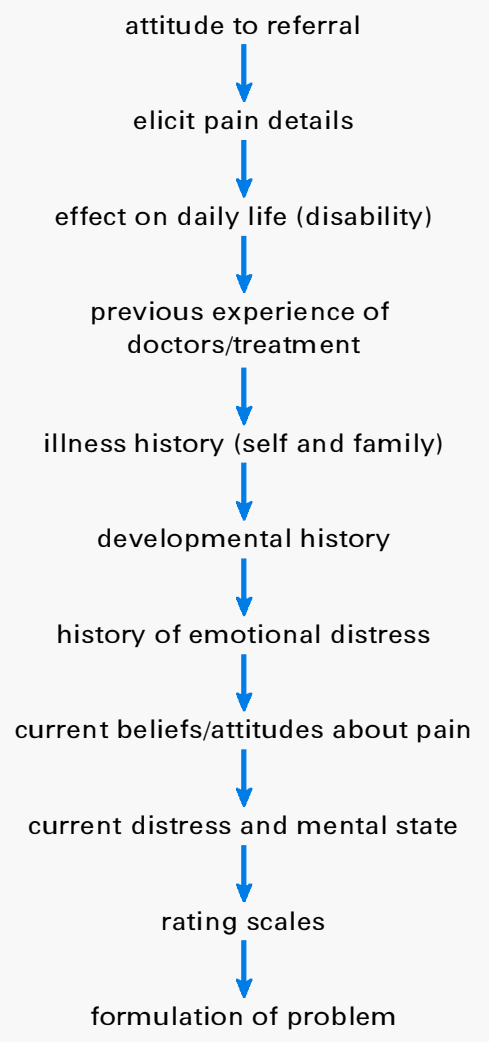

psychotropic or other drug use, and to quantify the amount of analgesic and psychotropic drugs taken during the day, as well as previous analgesic use, with comments on drug effectiveness. There should be routine enquiry about the use of alcohol, as well as over-the-counter (non-prescribed) drugs, and 'street' drugs such as cannabis.

It is important to interview any carers, partners or spouses for their opinions about the patient's pain - indeed, it is advisable to involve the patient's relatives in the management plan from the outset, reducing the risk of early relapse after discharge from hospital ${ }^{5}$.

\section{Assessment of pain behaviours}

Patients display a range of reactions to pain, some of which are observable (Table 3$)^{6}$. Learned pain behaviours should not be mistaken for malingering. Malingering is the conscious and purposeful faking of a symptom to achieve some benefit, usually financial. Most patients who display learned pain behaviours are not aware of doing so, whereas malingering patients may intentionally exhibit exaggerated behaviours indica- tive of pain. There is only limited evidence that outright faking of pain for financial gain is widespread. If the exaggeration is deliberate, it is often difficult to determine whether it represents an 'attempt to convince' or an 'attempt to deceive' the clinician, especially if the patient is being examined in a medico-legal context ${ }^{7}$.

\section{Use of standard rating scales}

It is often helpful at this stage to use rating scales in an attempt to quantify the physical and psychological symptoms. Both the Hospital Anxiety and Depression (HAD) scale ${ }^{8}$ and the Illness Perception Questionnaire (IPQ) ${ }^{9}$ (which yields important information about the patient's beliefs and expectations) are useful, as is a baseline rating of the patient's level of functional disability using either the short form 36 Health Survey Questionnaire $(\mathrm{SF} 36)^{10}$ or the Dartmouth COOP Scale ${ }^{11}$.

\section{Referral}

If the patient is being referred for psychological treatment, three important

Table 3. Pain behaviours (adapted from Ref 6).

$\begin{array}{ll}\text { Verbal/vocalisation } & \text { Sighs, moans } \\ \text { Motor } & \text { Repeated complaints } \\ & \text { Facial grimacing } \\ & \text { Distorted gait (limping) } \\ & \text { Rigid or unstable posture } \\ & \text { Excessively slow or laboured movement } \\ & \text { Take medication } \\ \text { Seek help/reduce pain } & \text { Use of protective device (crutches, cervical collar, } \\ & \text { wheelchair) } \\ & \text { Visit doctor } \\ \text { Functional limitation } & \text { Resting } \\ & \text { Reduced activity }\end{array}$

Table 4. Flexible management of chronic pain.

\begin{tabular}{|c|c|}
\hline Symptom-oriented & $\begin{array}{l}\text { Relaxation } \\
\text { Antidepressant drugs } \\
\text { Conventional analgesics }\end{array}$ \\
\hline Behaviourally oriented & Reduction of inappropriate healthcare use \\
\hline Function-oriented & $\begin{array}{l}\text { Pain management } \\
\text { Graded increase in activity }\end{array}$ \\
\hline Aetiologically oriented & $\begin{array}{l}\text { Cognitive therapy } \\
\text { Psychodynamic therapy }\end{array}$ \\
\hline Containment and support & Limit patient expectations of cure \\
\hline
\end{tabular}



referral:

- All necessary investigations should have been completed.

- The patient should be informed that a pain- or symptom-free existence may not be a realistic outcome.

- There should be a clear and honest explanation of the reasons for psychological referral.

The aims and goals of treatment should be made explicit from the outset. Some patients have chronic, intractable problems unlikely to respond to a brief, focused, psychological approach (Table 4).

\section{Management}

The interviewer should try to produce a formulation, distinguishing between predisposing, precipitating and maintaining factors. Management should focus on the last, which may include various factors (Table 5).

Various treatment approaches are available and can be divided into:

- psychological treatment, which includes cognitive-behavioural therapy $(\mathrm{CBT})^{12}$ or psychodynamic psychotherapy $^{13}$, and

- pharmacological treatment. issues need to be addressed before

Table 5. Maintaining factors in pain: the treatment focus.

- Depression, anxiety and panic disorder

- Dependent or avoidant personality disorder

- Chronic marital and/or interpersonal discord

- Occupational factors

- latrogenic factors (eg overinvestigation, unnecessary surgery)

- Abnormal illness beliefs (in patient and family)

- Chronic inactivity, leading to muscle weakness, joint stiffness and unfitness

- Compensation, litigation and benefits
The choice of treatment approach depends to a large extent on the orientation of the treating clinician and the available resources. Cognitive behavioural approaches tackle dysfunctional beliefs and abnormal behaviour, exemplified by a patient with fibromyalgia or chronic widespread pain spending all day in bed and avoiding exercise. Such a patient is not only asked about his/her illness beliefs - and encouraged to provide alternative explanations for them but also encouraged to carry out graded exercise, in particular gradually increasing periods out of bed ${ }^{14}$.

It is often appropriate to prescribe tricyclic antidepressants, especially if sleep disturbance is a problem. These have been shown to have analgesic effects independent of their antidepressant

\section{Key Points}

An important part of the clinical interview involves encouraging the patient to describe patterns of pain and behaviour on a hourly basis throughout a typical day. This may provide evidence of disability and mood disorder

Standard rating scales are useful adjuncts to the clinical assessment, providing measures of distress, beliefs about illness and disability

latrogenic factors (eg overinvestigation, inappropriate reassurance, unnecessary surgery, polypharmacy) can act as important maintaining factors for chronic pain

Outright faking of pain for financial gain is rare, but exaggeration is not, especially if the patient is involved in litigation. It is often difficult to determine whether this represents an attempt to convince or to deceive the clinician

More than one treatment modality may be used in patients with chronic pain (eg tricyclic antidepressants for analgesic and antidepressant effect and cognitive behavioural treatment with emphasis on changing pain beliefs and increasing physical activity)

KEY WORDS: chronic pain, chronic widespread pain, cognitive behavioural therapy, liaison psychiatry, musculoskeletal pain, pain behaviours, pain clinics, pain management groups, somatisation disorder $\operatorname{action}^{15}$, and it is important to explain this to the patient. Other 'unconventional analgesics' such as antiepileptic drugs may also have a role, as may conventional analgesics if used sensibly. In practice, both psychological and drug treatments are often used concurrently according to the needs of each patient.

\section{Occupational and social factors}

The workplace may cause both psychological and physical stress. Negotiation with occupational physicians or employers can be important in achieving a return to work $^{16}$. Prior dissatisfaction with employment is a major potential obstacle to rehabilitation ${ }^{17}$. A gradual return to full duties is helpful, but not all employers are sympathetic. Entitlement to benefits may also prove a barrier to rehabilitation.

\section{Management of chronic intractable pain}

A long-term strategy is required for a subgroup of patients with chronic enduring pain, characterised by high somatic awareness and a predisposition to develop physical symptoms at times of stress. Such patients, many of whom become severely disabled despite the absence of conspicuous disease, may require long-term supportive, empathic management designed to improve self-esteem and self-efficacy ${ }^{18}$. It is unclear who should best manage these patients and for how long: should it be the responsibility of the general practitioner, hospital doctor, pain specialist or psychiatrist? In practice, much depends on local resources, but good communi- 
Table 6. Indications for group treatment.

- No gross personality disorder or mental illness

- No continuing drug or alcohol misuse

- Motivated to improve, but not expecting cure

- Supportive relatives

- Able to commit to regular attendance

- Willing to work in a group

- Able to communicate

cation is vital, and case conferences and combined clinics can be useful.

\section{Pain management groups}

These are an important but limited resource, and selective referral to such a group may be appropriate. The physician should be aware of the usual inclusion criteria for these programmes (Table 6). Inpatient programmes are more expensive, but possibly more effective. In either case, the emphasis is on coping rather than curing, the group being run by clinical psychologists with physiotherapy input. Core components include education, goal-setting, graded exercise, activity pacing, relaxation training and problem-solving. The aim is to enhance self-efficacy, improve mood and function, and reduce dependency on drugs and doctors.

\section{Conclusions}

Chronic pain, whatever its cause, is a difficult experience for patients, families, and often for doctors. Management which combines the skills of the pain specialist, the liaison psychiatrist and the clinical psychologist is most likely to be effective.

\section{References}

1 Croft P, Rigby AS, Boswell R, Schollum J, Silman A. The prevalence of chronic widespread pain in the general population. J Rheumatol 1993;20:710-3.

2 Sullivan MD, Turner JA, Romano J. Chronic pain in primary care. Identification and management of psychosocial factors. Review. J Fam Pract 1991;32:193-9.

3 Gill D, Bass C. Somatoform and dissociative disorders: assessment and treatment. $A d v$ Psychiatr Treat 1997;3:9-16.

4 Barsky AJ. A comprehensive approach to the chronically somatizing patient. Review. J Psychosom Res 1998;45:301-6.

5 Benjamin S, Mawer J, Lennon S. The knowledge and beliefs of family care givers about chronic pain patients. J Psychosom Res 1992;36:211-7.

6 Turk DC, Okifuji A. Assessment of patients' reporting of pain: an integrated perspective. Review. Lancet 1999;353:1784-8.

7 Main C. The nature of chronic pain: a clinical and legal challenge. In: Halligan $\mathrm{P}$, Bass C, Oakley D (eds). Malingering and illness deception. Oxford: Oxford University Press (in press).

8 Zigmond AS, Snaith RP. The hospital anxiety and depression scale. Acta Psychiatr Scand 1983;67:361-70.

9 Weinman J, Petrie K, Moss-Morris R, Horne R. The Illness Perception Questionnaire: a new method for assessing the cognitive representation of illness. Psychol Health 1996;11:431-45.

10 Ware JE, Sherbourne CD. The MOS 36-item short-form health survey (SF-36): I. Conceptual framework and item selection. Med Care 1992;30;473-83.

11 Jenkinson C, Mayou R, Day A, Garratt A, Juszczak E. Evaluation of the Dartmouth COOP charts in a large-scale community survey in the United Kingdom. J Public Health Med 2002;24:106-11.

12 Morley S, Eccleston C, Williams A. Systematic review and meta-analysis of randomized controlled trials of cognitive behaviour therapy and behaviour therapy for chronic pain in adults, excluding headache. Pain 1999;80:1-13.

13 Guthrie E, Creed F, Dawson D, Tomenson B. A controlled trial of psychological treatment for the irritable bowel syndrome. Gastroenterology 1991;100:450-7.

14 Sharpe M. Cognitive behavioural therapies in the treatment of functional somatic symptoms. In: Mayou RA, Bass C, Sharpe M (eds). Treatment of functional somatic symptoms. Oxford: Oxford University Press, 1995:122-43.

15 McQuay HJ, Moore RA. Antidepressants and chronic pain. BMJ 1997;314:763-4.
16 Henderson M, Holland-Elliot K, Hotopf M, Wessely S. Liaison psychiatry and occupational health. Occup Med (Lond) 2001;51: 479-81.

17 Hotopf M. Occupational factors and unexplained physical symptoms. Adv Psychiatr Treat 1998;4:51-8.

18 Bass C. Management of somatisation disorder. Prescribers J 1996;36:198-205. 